\title{
ON APPROXIMATE DERIVATIONS
}

\author{
ROMAN BADORA
}

Abstract. Let $\mathscr{A}_{1}$ be a subalgebra of a Banach algebra $\mathscr{A}$ and let $f: \mathscr{A}_{1} \rightarrow \mathscr{A}$ satisfies

$$
\|f(x+y)-f(x)-f(y)\| \leqslant \delta \text { and }\|f(x \cdot y)-x \cdot f(y)-f(x) \cdot y\| \leqslant \varepsilon,
$$

for all $x, y \in \mathscr{A}_{1}$ and for some constants $\delta, \varepsilon \geqslant 0$. Then we prove that there exists a unique derivation $d: \mathscr{A}_{1} \rightarrow \mathscr{A}$ such that

$$
\|f(x)-d(x)\| \leqslant \delta, \quad x \in \mathscr{A}_{1}
$$

and

$$
x \cdot(f(y)-d(y))=0, \quad x, y \in \mathscr{A}_{1} .
$$

Moreover, we also prove the Rassias type stability result for derivations.

Mathematics subject classification (2000): 39B82.

Key words and phrases: derivation, stability, superstability.

\section{REFERENCES}

[1] S. CZERwIK, Stability Functional Equations of Ulam - Hyers - Rassias Type, Hadronic Press Inc., Palm Harbor, Florida, USA, 2003.

[2] Z. GAJDA, On stability of additive mappings, Internat. J. Math. \& Math. Sci., 14, (1991), 431-434.

[3] D. H. HYERS, On the stability of the linear functional equation, Proc. Nat. Acad. Sci. U.S.A. 27, (1941), 222-224.

[4] D. H. Hyers, G. IsAC AND Th. M. Rassias, Stability of Functional Equations in Several Variables, Birkhäuser, Boston - Basel - Berlin, 1998.

[5] G. IsAC, TH. M. RASSIAS, On the Hyers - Ulam stability of $\psi$-additive mappings, J. Approx. Theory 72, (1993), 131-137.

[6] Soon-Mo Jung, Ulam - Hyers - Rassias Stability of Functional Equations in Mathematical Analysis, Hadronic Press Inc., Palm Harbor, Florida, USA, 2001.

[7] TH. M. RASSIAS, On the stability of the linear mapping in Banach spaces, Proc. Amer. Math. Soc. 72, (1978), 297-300.

[8] P. ŠEMRL, The functional equation of multiplicative derivation is superstable on standard operator algebras, Inegr. Equat. Oper. Th., 18, (1994), 118-122.

[9] S. M. Ulam, A Collection of Mathematical Problems, Interscience, New York, 1960. 